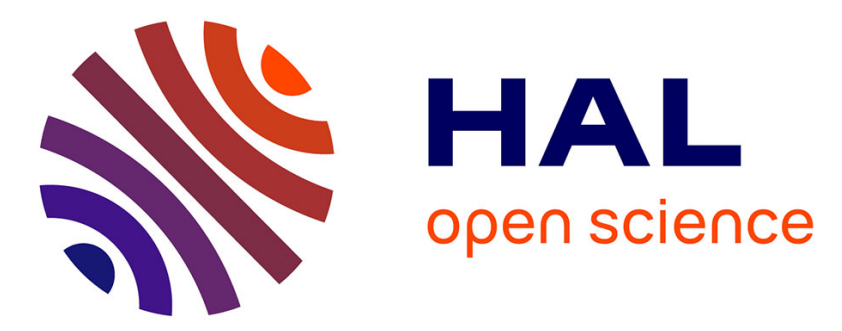

\title{
Age-related changes in conventional road versus off-road triathlon performance
}

\author{
Romuald Lepers, P.J. Stapley
}

\section{To cite this version:}

Romuald Lepers, P.J. Stapley. Age-related changes in conventional road versus off-road triathlon performance. European Journal of Applied Physiology, 2011, 111 ((8)), pp.1687-1694. hal-00702344

\section{HAL Id: hal-00702344 \\ https://u-bourgogne.hal.science/hal-00702344}

Submitted on 30 May 2012

HAL is a multi-disciplinary open access archive for the deposit and dissemination of scientific research documents, whether they are published or not. The documents may come from teaching and research institutions in France or abroad, or from public or private research centers.
L'archive ouverte pluridisciplinaire HAL, est destinée au dépôt et à la diffusion de documents scientifiques de niveau recherche, publiés ou non, émanant des établissements d'enseignement et de recherche français ou étrangers, des laboratoires publics ou privés. 
European Journal of Applied Physiology, 2011, 111(8):1687-1694

\section{Age-related changes in conventional road versus off-road triathlon performance}

\section{Romuald Lepers ${ }^{1}$ \& Paul J. Stapley ${ }^{2}$}

${ }^{1}$ University of Burgundy, Faculty of Sport Sciences, INSERM U887, BP 27877, 21078 Dijon Cedex, FRANCE

${ }^{2}$ Balance and Voluntary Movement Lab, Department of Kinesiology and Physical Education, McGill University, 475 Pine Ave West, Montreal, Quebec, H2W1S4, CANADA

Running title: Age and Performance in off-road triathlon

Corresponding author:

\section{Romuald Lepers}

Université de Bourgogne

Faculté des Sciences du Sport

INSERM U887

BP 27877

21078 Dijon Cedex

France

Tel : +33.3 .80 .39 .67 .60$

Fax : +33.3.80.39.67.02

Email : romuald.lepers@u-bourgogne.fr 


\begin{abstract}
The aims of this study were: i) to analyze age-related declines in swimming, cycling, and running performances for road-based and off-road triathlons, and ii) to compare age-related changes in these three disciplines between road-based and off-road triathlons. Swimming, cycling, running and total time performances of the top 5 males between 20 and 70 years of age (in 5 year intervals) were analyzed for short distance road-based $(1.5 \mathrm{~km}$ swim, $40 \mathrm{~km}$ cycle, and $10 \mathrm{~km}$ run) and off-road (1.5 km swim, $30 \mathrm{~km}$ mountain bike, and $11 \mathrm{~km}$ trail run) triathlons at the 2009 World Championships. Independently of age, there was a lesser agerelated decline in cycling performance $(\mathrm{P}<0.01)$ compared to running and swimming for roadbased triathlon. In contrast, age-related decline did not differ between the three locomotion modes for off-road triathlon. With advancing age, the performance decline was less pronounced $(\mathrm{P}<0.01)$ for road-based than for off-road triathlon in swimming $(\geq 65$ years), cycling ( $\geq 50$ years), running ( $\geq 60$ years), and total event ( $\geq 55$ years) times, respectively. These results suggest that the rate of the decline in performance for off-road triathlon is greater than for road-based triathlon, indicating that the type of discipline (road versus mountain bike cycling and road versus trail running) exerts an important influence on the magnitude of the age-associated changes in triathlon performance.
\end{abstract}

Keywords: Master athlete, Swimming, Cycling, Mountain biking, Running, Xterra ${ }^{\circledR}$, 


\section{Introduction}

The age-related decline in endurance running performance up to the marathon distance has been well documented (e.g. Trappe 2007, Tanaka \& Seals 2008). In general, peak endurance performance is maintained until $\sim 35$ years of age, followed by modest decreases until 50-60 years of age, and a progressively steeper decline thereafter (Tanaka \& Seals 2008). In contrast, less is known about the age-related decline in performance of other modes of locomotion such as swimming (Donato et al. 2003) and cycling (Balmer et al 2008a,b). The nature and the type of muscular contractions differ between the three modes of locomotion (swimming, cycling, and running). For example, cycling is a non-weight bearing activity that employs predominantly concentric muscle activation compared with the stretch-shortening activity and eccentric activations during running. Swimming involves mostly the upper body musculature with no mechanical constraints. Therefore, questions about whether age-related declines in performance differ between the modes of locomotion may be raised.

Triathlon, involving successive swimming, cycling and running bouts of exercise, represents an interesting model to examine the age-related changes in endurance performance in these different locomotion modes (Bentley et al. 2002). It has been shown that the agerelated declines in performance times were specific for each locomotion mode. For example, there is a lesser age-related decline in cycling performance compared with running and swimming performances for both short (1.5 km swim, $40 \mathrm{~km}$ cycling, and $10 \mathrm{~km}$ running) and long (3.8 km swim, $180 \mathrm{~km}$ cycling, and $42.2 \mathrm{~km}$ running) distance triathlons (Bernard et al 2010, Lepers et al. 2010). One explanation for the different age-related declines in cycling and running may involve the mechanical power required by these disciplines. Mechanical power output in running depends on the velocity $(\mathrm{P}=\mathrm{k} . \mathrm{V})$ while it depends on third power of velocity in cycling $\left(\mathrm{P}=\mathrm{k} \cdot \mathrm{V}^{3}\right)$. If we assume that the changes in aerobic capacity (e.g. $\mathrm{VO}_{2}$ 
max) with age are directly related to the decline in mechanical power, a similar reduction in power output for running and cycling with advancing age would induce a lower reduction in cycling velocity than running velocity (Lepers et al. 2010). This may explain, in part, why the magnitude of the decrease in cycling performance with age was less than that for running. In addition, the lesser decline in cycling performance with advancing age could also be due to a lesser reduction in lactate threshold and/or economy compared with running.

In addition, it has been shown that in contrast to swimming, the magnitude of the declines in cycling and running performances with age in short distance triathlon were less pronounced than for long distance races (Lepers et al. 2010). Greater neuromuscular fatigue, greater muscle damage, and changes in substrate availability and utilisation with age could explain the task duration effect on triathlon performances at least in cycling and running.

In the field of endurance multisport, off-road triathlon (also named Xterra®) combining swimming, mountain biking (MTB) and trail running represents another interesting model to examine the age-related changes in endurance performance in different locomotion modes. Since 1996, the world's premier off-road triathlon, also named the Xterra ${ }^{\circledR}$ World championship, has comprised a $1.5 \mathrm{~km}$ swim, a $30 \mathrm{~km}$ MTB ride, and a $11 \mathrm{~km}$ trail run, and has taken place on the island of Maui (Hawaii, USA), (Lepers \& Stapley, 2010). In contrast to conventional (road-based) triathlon, cycling and running parts of off-road triathlon take place on trails, with frequently significant ascents in the cycling leg of the race. The major difference between off-road and conventional triathlon is found in the cycling discipline, which is performed as MTB during off-road triathlon. Physiological and technical requirements of mountain biking differ in many points from road cycling. Factors other than aerobic power and capacity such as off-road cycling economy, anaerobic power and capacity, and technical ability might influence off-road cycling performance (Impellizzeri \& Marcora, 2007). Similarly, running on trails is specific and also requires more technical ability than 
road running (Anderson et al. 2009, Hoffman \& Wegelin 2009). During off-road triathlon, the age-related declines in cycling and running performances maybe greater because the physiological and mechanical stresses that occur during off-road triathlon are much greater compared to those encountered during road-based triathlon.

Therefore, the purposes of this study were: 1 ) to determine if there was a reduced rate of decline in cycling performance with advancing age compared to running and swimming for the off-road triathlon, as has been previously shown for road-based triathlons (Bernard at al. 2010, Lepers et al. 2010), and 2) to compare age-related changes in swimming, cycling, and running performances between the road-based and off-road triathlons. Due to the nature of the disciplines with stochastic efforts (i.e. with a greater anaerobic component), mountain biking and trail running require different physiological and technical aptitudes compared to conventional triathlon cycling and running. We therefore hypothesized that age-related declines in cycling and running performance would be greater for off-road than for conventional road-based triathlon.

\section{Methods}

Approval for the project was obtained from the Burgundy University Committee on Human Research. This study involved the analysis of publicly available data so content was waived.

Averaged swimming, cycling, and running and overall time performances of the top 5 amateurs of ten male age groups were analyzed for road-based (short distance) and off-road triathlon World Championships in 2009. The age groups distinguish the categories for each period of 5 years as follows: 20-24 yrs, 25-29 yrs, 30-34 yrs, 35-39 yrs, 40-44 yrs, 45-49 yrs, 50-54 yrs, 55-59 yrs, 60-64, and 65-69 yrs. 
For the road-based short distance triathlon, the data set was obtained from the 2009 World Championships web site (http://www.worldtriathlongoldcoast.com/). This race took place at the Gold Coast, Australia ; the road-based World Championships was a point-to-point race, combining a $1.5 \mathrm{~km}$ swim in the ocean with wetsuit (Water temperature: $21^{\circ} \mathrm{C}$ ), a $40 \mathrm{~km}$ (2 laps of $20 \mathrm{~km}$ ) road bike ride almost flat (altitude change $<5 \mathrm{~m}$ ) and a $10 \mathrm{~km}$ flat run on the road along the ocean. The race took place on September $12^{\text {th }} 2009$; during the race ambient temperature and relative humidity were about $22^{\circ} \mathrm{C}$ and $65 \%$, respectively.

For the off-road (Xterra) triathlon, the data set was obtained from the Xterra triathlon World Championships web site: http://www.xterraplanet.com/maui/past.html. Since 2005 the Xterra World Championships has taken place in Makena, Maui (Hawaii, USA) and held each year in October with only minor changes to the course. The championships is a point-to-point race, combining a $1.5 \mathrm{~km}$ swim in the Pacific ocean without wetsuit (Water temperature: $28^{\circ} \mathrm{C}$ ), a $30 \mathrm{~km}$ MTB ride that involves a total altitude change of $915 \mathrm{~m}$ on rocky, dirt-strewn trails on the lower slopes of Haleakala Volcano, and a $11 \mathrm{~km}$ trail run along the beaches and lava formations along south Maui's scenic south shore (total altitude change of $346 \mathrm{~m}$ ) (Lepers \& Stapley, 2010). The Xterra Maui triathlon is the last in a series of nearly 20 offroad triathlons held in the world that serve as qualifying races. The race took place on October $25^{\text {th }} 2009$; during the race ambient temperature and relative humidity were about $28^{\circ} \mathrm{C}$ and $60 \%$, respectively.

For both based-road short distance and off-road triathlons, the swimming, cycling, running and overall time performances of each triathlete finishing in the top 5 of each age group was normalized to the mean time performance of the top 5 of the best performing age group. Thus, the age-related declines in performance were expressed using a ratio calculated 
between the individual and the mean time performances of the best performing age group for each mode of locomotion and total event time.

Statistical analysis

Data are reported as means \pm SD in the text and table and displayed as means \pm SE in the figures. A two-way ANOVA with repeated-measures on locomotion mode was used to compare performance ratio between modes of locomotion across ages for road-based and offroad triathlons. For each mode of locomotion and total time performance, a two way ANOVA (age $\mathrm{x}$ type of triathlon) was used to compare performance ratios between road-based versus off-road triathlon across age. Post hoc analysis (Tukey) was used to test for differences within the ANOVAs when appropriate. A significance level of $P<0.05$ was used to identify statistical significance.

\section{Results}

At the road-based triathlon World Championship, there were 1537 finishers: 925 males (60\%) and 612 females (40\%), and the finishing rate was $97.4 \%$. At the off-road triathlon World Championships, there were 486 finishers: 336 males (69\%) and 150 females (31\%), and the finishing rate was $94.5 \%$.

Swimming, cycling, running and total time performances for each age group for both roadbased and off-road triathlons are presented in Table 1 . The relative contribution of each part of the overall performance remained constant across the ages but differed slightly between the two triathlon types. For off-road triathlon, the relative contribution of the swim part was lower while the cycle part was greater compared to road-based triathlon. For road-based triathlon, 
the $1.5-\mathrm{km}$ swimming, 40-km cycling, and 10-km running represented on average $17.3 \pm 0.8$, $49.1 \pm 1.2,31.2 \pm 1.2 \%$ of the total time, respectively. For off-road triathlon, the $1.5-\mathrm{km}$ swimming, 30-km mountain biking, and 11-km running represented on average $12.7 \pm 1.2$, $57.8 \pm 1.9,29.4 \pm 2.0 \%$ of the total time, respectively.

Standard deviations of mean values for each locomotion mode and for total time performances were greater for off road triathlon compared to road-based triathlon, suggesting that the density of the top 5 was lower for off-road triathlon.

(Insert table 1)

For both road-based and off-road triathlons, the performance ratios for each mode of locomotion decreased in a curvilinear manner with advancing age (Figures 1A and 1B). For road-based triathlon (Figure $1 \mathrm{~A})$, there was a locomotion mode effect $(\mathrm{F}=12.9, \mathrm{P}<0.0001)$ for performance ratio. Independently of age, both swimming and running performance ratios were lower $(\mathrm{P}<0.01)$ than cycling performance ratios. In addition, independently of locomotion mode, performance ratio differed between the age groups $(\mathrm{F}=117.2, \mathrm{P}<0.0001)$. Performance ratio was significantly lower $(\mathrm{P}<0.01)$ for age groups $45-49 \mathrm{yrs}$ and above compared to all age groups between 20-24 yrs and 35-39 yrs. Finally, there was a significant interaction between age and mode of locomotion for performance ratio $(\mathrm{F}=2.5, \mathrm{P}<0.002)$. For off-road triathlon however, there was no interaction between age and mode of locomotion $(\mathrm{F}=1.45, \mathrm{P}=0.13)$ and there was no locomotion mode main effect $(\mathrm{F}=0.29, \mathrm{P}=0.74)$ for performance ratio. However, independently of locomotion mode, performance ratio differed between the age groups $(\mathrm{F}=31.9, \mathrm{P}<0.0001)$. Performance ratio was significantly lower $(\mathrm{P}<$ 0.01) for age groups 55-59 yrs and above compared to all previous age groups comprised between 20-24 yrs and 40-44 yrs. 
(Insert Figures $1 \mathrm{~A} \& 1 \mathrm{~B})$

Comparisons of age-related declines in swimming, cycling, running and total performance for road-based and off-road triathlons are shown in Figure 2. There was a significant interaction between age and type of triathlon for swimming $(\mathrm{F}=2.85, \mathrm{P}=0.01)$, cycling $(\mathrm{F}=10.03, \mathrm{P}<$ 0.0001), running $(\mathrm{F}=5.36, \mathrm{P}<0.0001)$, and total event $(\mathrm{F}=12.04, \mathrm{P}<0.0001)$ performance ratio. Age-related declines in performance were less pronounced for road-based compared to off-road triathlon for swimming for age group 65-69 yrs, for cycling for age groups 50-54 yrs and above, for running for age groups 60-64 yrs and 65-69 yrs and for total time for age groups 55-59 yrs and above, respectively.

(Insert Figure 2)

\section{Discussion}

The main findings of the present study were i) a reduced age-related decline in cycling performance compared to running and swimming performances for road-based triathlon but not for off-road triathlon, and ii) a smaller effect of age on swimming, cycling and running performances for road-based compared to off-road triathlon.

\section{Methodological considerations}

With endurance events, the environment (temperature, humidity, precipitation) affects the outcome of the results. For road-based triathlon taking place on the Gold Coast (Australia), the temperature was around $22^{\circ} \mathrm{C}$, whereas during the off-road triathlon taking place in Hawaii (USA), the temperature was around $28^{\circ} \mathrm{C}$. Thus, the hotter conditions for the 
off-road triathlon may have more greatly affected performance than for the road-based triathlon. However, by normalizing the individual time performance by the mean time performance of the top 5 of the best performing age groups for both type of triathlons, the influence of environment was minimized when comparing road-based and off road triathlon performances.

The present paper focuses on the performances of male triathletes only. Potential differences in age-related decline in triathlon performance between male and female may also occur (e.g. Vleck et al. 2008, Lepers \& Maffiuletti, 2010), so it could be interesting to verify if similar results are obtained for female triathletes. However, for off-road triathlon, data for female triathletes older than 55 years of age are limited. Moreover, unpublished data from our laboratory suggest that similar findings are observed for female triathletes i.e. a reduced agerelated declines in cycling performance compared with running and swimming performances for road-based triathlon but not for off-road triathlon and a greater magnitude of age-related decline in performance for the off-road triathlon than for the road-based triathlon.

The present data do not include performance of elite/professional triathletes. This is because differences existed between the race formats for off-road and road events. At the World off-road triathlon Championships, elite and age grouper triathletes raced the same course at the same time; at the World road-based short distance triathlon Championships, elite triathletes raced a different course with different rules (drafting allowed for the elite athletes and forbidden for the age groupers).

Age-related differences in triathlon performance differ between road-based versus off-road triathlon 
Age-related declines in swimming, cycling and running performances were lesser for road-based triathlon than for off-road triathlon. Lepers et al. (2010) found that age-related changes in swimming performance were not influenced by task duration; indeed the magnitudes of decreases in swimming performance were similar for short distance versus long distance triathlon. The swimming distance was similar between road-based and off-road triathlon (i.e. $1.5 \mathrm{~km}$ ) but for road-based triathlon wetsuits were permitted while for off-road triathlon they were forbidden as the water temperature was close to $28^{\circ} \mathrm{C}$. The use of wetsuits may explain firstly the fastest swimming times at the road-based triathlon than at the off-road triathlon World Championships (see table 1), and secondly the lower declines in performance at older ages for road-based triathlon. Indeed, wearing a wetsuit improves swimming performance and propulsion efficiency, but also reduces gross energy consumption in the swimming portion of triathlon races (Tomikawa et al., 2008). We unfortunately had no possibility of testing the swimming abilities of road-based and off-road triathletes. However, if one assumes that the advantage of wearing a wetsuit may be greater for slower swimmers (and therefore oldest swimmers) compared to the faster (younger) ones, this could explain the lower declines in swimming performance at older ages for road-based triathlon where wetsuits were used. On average, for off-road triathlon swimming performance (without wetsuits), declined by $\sim 16 \%$ at 55 years old, and reached $\sim 37 \%$ by 65 years of age. The present decline is somewhat greater than those found by Tanaka \& Seals (1997) $(\sim 32 \%$ at 65 yrs age) at the same distance swum in a swimming pool. The lower performance declines observed by these authors for the same age compared with the triathlon data might be due the differences between the water conditions: calm in swimming pool versus stochastic in open water for triathlon.

For road-based short distance triathlon, there was a lesser age-related decline in cycling performance compared to running and swimming performances. Similar findings have 
been already documented by Bernard et al. (2010) for short distance triathlon and by Lepers et al. (2010) for long distance triathlon. In contrast, for off-road triathlon, cycling (mountain biking) performance declined with advancing age in the same manner to that seen in swimming and running. The absence of relative preservation of cycling performance with advancing age for off-road triathlon suggests that the effect of age on cycling performance is amplified for mountain biking compared to road cycling.

Indeed, the magnitude of the declines in cycling performance with advancing age for road-based triathlon was less pronounced than for off-road triathlon. It has been shown that task duration in triathlon exerts an influence on age-related declines in triathlon performance. Lepers et al. (2010) showed that age-related decline in cycling performance was greater for long distance triathlon (180 km cycle) compared to short distance triathlon (40 km cycle). For example, these authors found that cycling performance declined by $\sim 20 \%$ for short distance triathlon and by $26 \%$ for long distance triathlon at 65 years, respectively. In the present study, cycling performance declined by $\sim 17 \%$ at 65 years for short distance triathlon and by $39 \%$ for off-road triathlon, respectively. The longer duration of mountain biking part of off-road triathlon $(\sim 2 \mathrm{~h})$ compared to road cycling part at short distance triathlon $(\sim 1 \mathrm{~h})$ may not totally explain the greater decline in cycling performance in off-road triathlon with advancing age. The nature of the discipline may better explain the greatest part of that difference.

Indeed, mountain biking differs in many respects from road cycling. The duration of the MTB leg $(\sim 2 \mathrm{~h})$ of the off-road triathlon is very similar to that of a cross-country MTB race for which it has been shown that more than $80 \%$ of the time is spent above lactate threshold (Impellizzeri et al. 2002). This very high intensity (i.e. above lactate threshold) is related in particular to climbs, forcing off-road cyclists to expend most of their effort going against gravity, greater rolling resistance associated with the difficult terrain conditions, and the isometric contractions of arm and leg muscles necessary for bike handling and 
stabilisation. Therefore, a known decrease in power-to-weight ratios with advancing age (Bonnefoy et al. 1998, Kostka, 2005) inevitably leaves older off-road triathletes with a disadvantage in the climbs compared to flat sections. Secondly, lower arm and leg muscle strength in older athletes (Faulkner et al. 2008) may also mean that they possess a reduced bike stabilisation capacity during the descents, even if decreases in muscle strength may be reduced in older athletes compared to sedentary persons of the same age (McCrory et al. 2009). Older triathletes even if they compete in off-road triathlon may probably be less experienced off-road cyclists compared to older mountain bikers. Finally, age-related changes in technical ability to control and stabilize the bicycle, if it exists (Sturnieks et al. 2008), could be another factor explaining the greater decline in MTB performance compared to road cycle performance.

The age-related declines in running performance were greater for off-road triathlon than for road-based triathlon. It has been suggested that in older athletes, skeletal muscle continues to have high aerobic potential, while declines in muscle size and contractile performance are apparent (Trappe 2007, Tanaka \& Seals 2008). These changes in the skeletal muscle profile may contribute partly to the alterations in running performance seen with increasing with age, but the difference in age-related changes in performances between trail versus road running remains unclear. Lepers et al. (2010) showed that the magnitude of the decline in running performance with advancing age was greater for long distance triathlon (42 $\mathrm{km}$ run) compared to short distance triathlon (10 km run). Indeed, running performance declined by $\sim 27 \%$ for short distance triathlon and by $33 \%$ for long distance triathlon at 65 years, respectively. In the present study, running performance declined by $\sim 22 \%$ at 65 years for short distance triathlon and by $35 \%$ for off-road triathlon. As for cycling, the longer duration of the trail running part during off-road triathlon $(\sim 1 \mathrm{~h})$ compared to the road running 
part during short distance triathlon $(\sim 40 \mathrm{~min})$ may explain only in part, the greater decline in running performance in off-road triathlon with advancing age.

Age-related changes in trail running performance have been few investigated and for distances much greater than $11 \mathrm{~km}$. For example, Easthope et al (2010) showed that performance of masters athletes ( 45 yrs of age) during a $55 \mathrm{~km}$ trail running race did not differ from those of young athletes ( $\sim 30$ yrs of age), and that both group of athletes showed similar fatigue and muscle damage after the race even if recuperation seemed slower in masters athletes. Hoffman \& Wegelin (2009) found that the finish times of a $161 \mathrm{Km}$ trail running race were about $40 \%$ longer for athletes of age 60-69 yrs compared to fastest athletes of age $30-40$ yrs.

The specificity of the $11 \mathrm{~km}$ trail run for the off-road triathlon with running part along the beaches and lava formations with a total altitude change of $346 \mathrm{~m}$ affected more the running performance compared to a $10 \mathrm{~km}$ flat road run but the reasons are unclear. Lower capacity to assimilate the variation in running intensity and lower ability to change the biomechanics of running (foot support, stride frequency) due to the changes in surface (sand, rocks, etc...) may explain the lower running performances of older triathletes during off-road triathlon compared to road-based triathlon. 


\section{Conclusion}

This cross sectional study found that the magnitudes of age-related declines in triathlon performance for off-road triathlon are greater than for road-based triathlon, suggesting that the type of discipline (swimming with or without wetsuit, road versus MTB cycling, and road versus trail running) exerts an important influence on the age-associated changes in triathlon performance. The specific aspects of mountain biking and trail running may explain why agerelated decline in off-road triathlon is more pronounced for off-road compared to conventional on road triathlon. Further studies examining the changes in training volume and physiological characteristics of older road-based and off-road triathletes are required to better understand the age-associated changes in triathlon performance and will provide valuable information for understanding the way to maintain physical capacity and performance with advanced age. In addition, future analysis of the age-related changes in performance for other endurance or ultra-endurance single discipline events, such as mountain bike races and trail or road running races, may also provide valuable insights into the maintenance of performance in older athletes.

\section{Conflict of interest}

The authors have non conflict of interests to report. 


\section{References}

Anderson LS Jr, Rebholz CM, White LF, Mitchell P, Curcio EP 3rd, Feldman JA, Kahn JH (2009) The impact of footwear and packweight on injury and illness among long-distance hikers. Wilderness Environ Med 20: 250-256

Balmer J, Bird S, Davison R (2008a) Indoor 16.1-km time-trial performance in cyclists aged 25- 63 years. J Sports Sci 26:57-62

Balmer J, Bird S, Davison R, Lucia A (2008b) Effect of age on 16.1-km time-trial performance. J Sports Sci 26:197-206

Bentley DJ, Millet GP, Vleck VE, MacNaughton LR (2002) Specific aspects of contempory triahlon: implications for physiological analysis and performance. Sports Med 32:345-359

Bernard T, Sultana F, Lepers R, Hausswirth C, Brisswalter J (2010) Age-related decline in Olympic triathlon performance: effect of locomotion mode. Exp Aging Res 36:64-78

Bonnefoy M, Kostka T, Arsac LM, Berthouze SE, Lacour JR (1998) Peak anaerobic power in elderly men. Eur J Appl Physiol 77:182-188

Donato AJ, Tench K, Glueck DH, Seals DR, Eskurza I, Tanaka H (2003) Declines in physiological functional capacity with age: a longitudinal study in peak swimming performance. J Appl Physiol 94:764-769

Easthope CS, Hausswirth C, Louis J, Lepers R, Vercruyssen F, Brisswalter J. (2010) Effects of a trail running competition on muscular performance and efficiency in well-trained young and master athletes. Eur J Appl Physiol 110: 1107-1116

Faulkner JA, Davis CS, Mendias CL, Brooks SV (2008) The aging of elite male athletes: agerelated changes in performance and skeletal muscle structure and function. Clin J Sport Med 18: $501-517$

Hoffman MD, Wegelin JA (2009) The Western states 100-mile endurance run: participation and performance trends. Med Sci Sports Exerc 41:2191-2198

Impellizzeri F, Marcora SM (2007) The physiology of mountain biking. Sports Med 37:59-71 Impellizzeri F, Sassi A, Rodriguez-Alonso M, Mognoni P, Marcora S (2002) Exercise intensity during off-road cycling competitions. Med Sci Sports Exerc 34:1808-1813

Kostka T. Quadriceps maximal power and optimal shortening velocity in 335 men aged 23-88 years (2005) Eur J Appl Physiol 95:140-155

Lepers R, Stapley P (2010) Differences in gender and performance in off-road triathlon. J Sports Sci [Epub ahead of print] 
Lepers R, Sultana F, Bernard T, Hausswirth C, Brisswalter J (2010) Age-related changes in triathlon performances. Int J Sports Med 31(4):251-256

Lepers R, Maffiuletti NA (2010) Age and Gender Interactions in Ultra-Endurance Performance: Insight from Triathlon. Med Sci Sports Exerc [Epub ahead of print] McCrory JL, Salacinski AJ, Hunt SE, Greenspan SL (2009) Thigh muscle strength in senior athletes and healthy controls. J Strength Cond Res 23:2430-2436.

Sturnieks DL, St George R, Lord SR (2008) Balance disorders in the elderly. Neurophysiol Clin 38: 467-478. Review.

Tanaka H, Seals DR (1997) Age and gender interactions in physiological functional capacity: insight from swimming performance. J Appl Physiol 82: 846-851

Tanaka H, Seals DR (2008) Endurance exercise performance in Masters athletes: ageassociated changes and underlying physiological mechanisms. J Physiol 586:55-63

Tomikawa M, Shimoyama Y, Nomura T (2008) Factors related to the advantageous effects of wearing a wetsuit during swimming at different submaximal velocity in triathletes. J Sci Med Sport 11: 417-423

Trappe S (2007) Marathon runners. How do they age? Sport Med 37:302-305

Vleck VE, Bentley DJ, Millet GP, Bürgi A (2008) Pacing during an elite Olympic distance triathlon: Comparison between male and female competitors. J Sci Med Sport 11: 424-432 


\section{Legends}

\section{Figure 1}

Age-related declines in swimming, cycling and running performances for road-based (Panel A) and off-road triathlons (Panel B), (mean \pm SE). For road-based triathlon, the swimming performance ratio for age groups 45-49 yrs and above was significantly different from the best age group (i.e. 20-24 yrs). The cycling performance ratio for age groups 55-59 yrs and above was significantly different from the best age group (i.e. 25-29 yrs). The running performance ratio for age groups 50-54 yrs and above was significantly different from the best age group (i.e. 20-24 yrs). For off-road triathlon, performance ratio differed between the age groups, independently of locomotion mode. Performance ratio was significantly lower for age groups 55-59 yrs and above compared to all previous age groups comprised between 2024 yrs and 40-44 yrs.

$*: \mathrm{P}<0.05, * *: \mathrm{P}<0.001$ : Cycling significantly different from running.

\section{Figure 2}

Age-related declines in swimming, cycling, running and total performances for road-based and off-road triathlons (mean $\pm \mathrm{SE}$ ). Age-related decline in swimming, cycling, running, and total performance was less pronounced for road-based triathlon.

$*: \mathrm{P}<0.05 ; * *: \mathrm{P}<0.01$ : Significantly different from off-road triathlon for the same age group. 

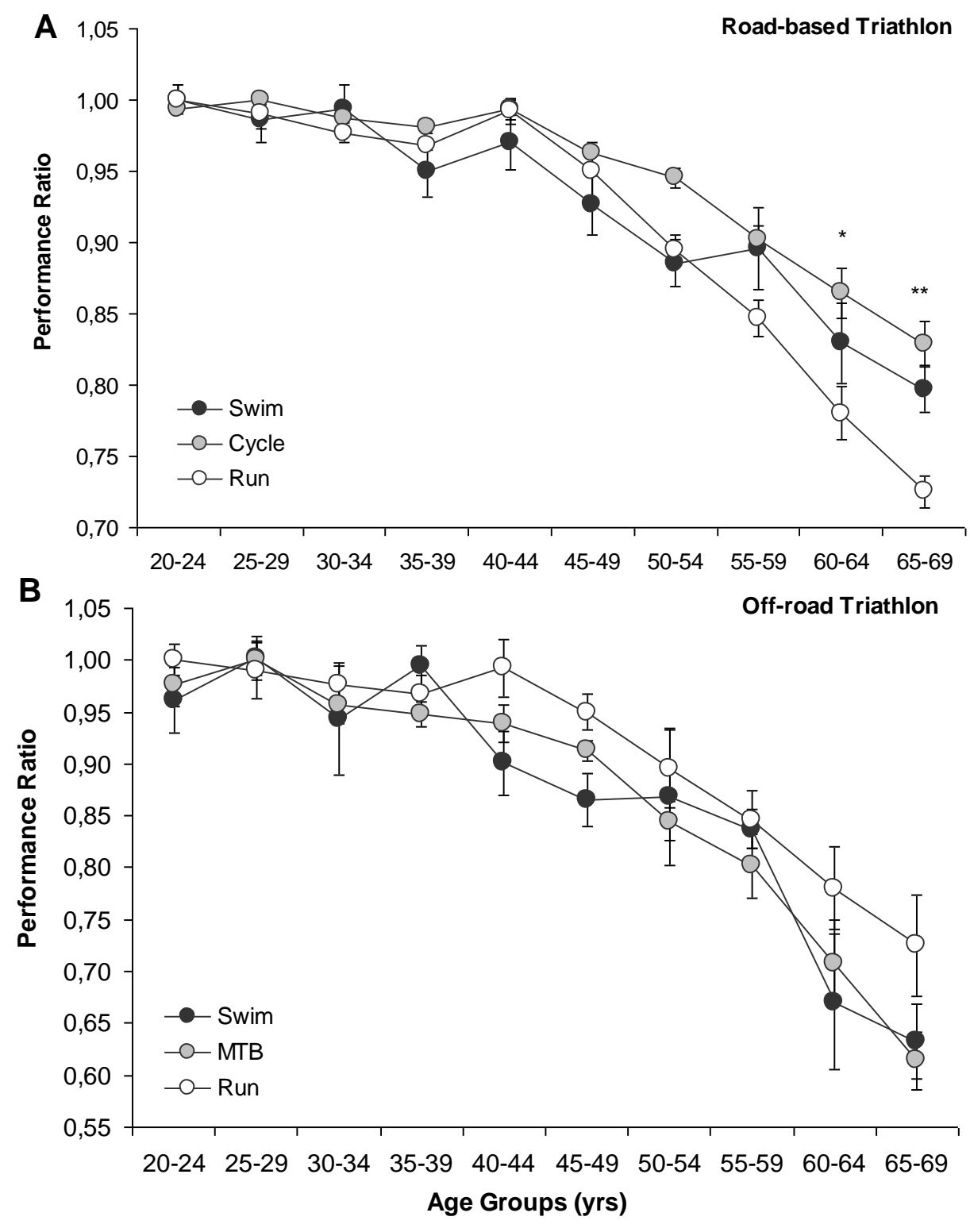

Figure 1 

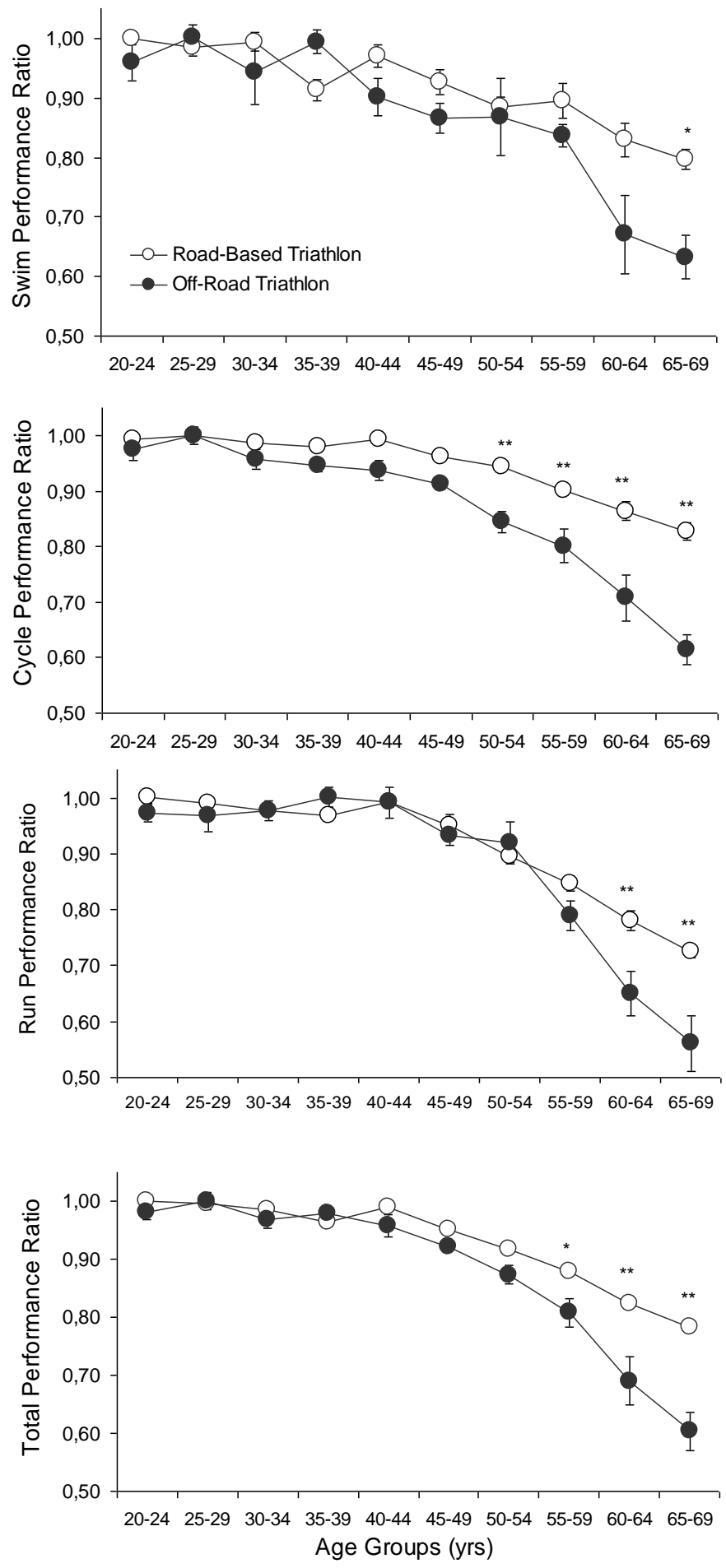

Figure 2 